\title{
The Effect of Financial Materiality on ESG Performance Assessment
}

\author{
Nicolas Madison and Eduardo Schiehll *(D) \\ HEC Montréal, 3000, Chemin de la Côte-Sainte-Catherine, Montréal, QC H3T 2A7, Canada; \\ nicolas.madison@hec.ca \\ * Correspondence: eduardo.schiehll@hec.ca
}

\section{check for}

updates

Citation: Madison, N.; Schiehll, E. The Effect of Financial Materiality on ESG Performance Assessment. Sustainability 2021, 13, 3652. https:// doi.org/10.3390/su13073652

Academic Editor: Renard Siew

Received: 16 February 2021

Accepted: 15 March 2021

Published: 25 March 2021

Publisher's Note: MDPI stays neutral with regard to jurisdictional claims in published maps and institutional affiliations.

Copyright: (c) 2021 by the authors. Licensee MDPI, Basel, Switzerland. This article is an open access article distributed under the terms and conditions of the Creative Commons Attribution (CC BY) license (https:// creativecommons.org/licenses/by/ $4.0 /)$.

\begin{abstract}
The effect of considering the financial materiality of ESG (environmental, social and governance) issues on firms' ESG performance scores and rankings is investigated using Morgan Stanley Capital International (MSCI) ESG Ratings and the financial Materiality Map ${ }^{\circledR}$ developed by the Sustainability Accounting Standard Board (SASB). Results show that when financial materiality is applied, firms' ESG performance scores change significantly. Further corroboration is provided by significant changes in firms' ESG rankings when ESG performance assessment is based on SASBadjusted ESG performance scores. Environmental pillar issues, and particularly natural resource use, are predominantly responsible for the changes. Overall, the results suggest that financial materiality affects the informative value of ESG scores and rankings, allowing the identification of investment opportunities in firms with high scores on business-critical ESG issues. We argue that consideration of financial materiality can better inform investment decisions based on ESG performance. This study adds to the understanding and assessment of ESG performance and its information content.
\end{abstract}

Keywords: ESG performance; materiality; ratings; rankings; social; environmental

\section{Introduction}

A recent and growing trend is the use of nonfinancial information to guide investment decisions. Thus, greater consideration is given to environmental, social and governance (ESG) factors. A study of an international sample of investors revealed that in $2016,68 \%$ of respondents frequently or occasionally considered firms' extra-financial ESG performance to make investment decisions, an increase of $11 \%$ over 2013 [1]. Similarly, Van Durren et al. [2] demonstrated that many conventional fund managers integrate ESG information into their decision process. One explanation for this heightened interest in ESG performance is the positive correlation with firms' financial performance, as demonstrated in metaanalyses $[3,4]$.

Investors can obtain ESG information from a variety of sources, such as rating agencies and index providers. Generally, however, experts advise both firms and rating agencies to focus more on material ESG issues that can directly affect the firm's bottom line $[1,5,6]$. Similarly, Khan et al. [7] showed that firms' investments in sustainable practices led to financial outperformance, but only when these investments were related to sustainability issues that were financially material to the firms. More importantly, after controlling for high performance in financially material ESG issues, the authors also showed that firms' investments in nonfinancially material issues did not lead to better financial performance but may instead have decreased performance. This suggests that materiality matters, and that it can affect the informativeness of ESG scores and ratings. Materiality refers to the relevance of information for stakeholder analysis and decision making. In the context of sustainability reports, the financial materiality criterion refers more precisely to the ESG issues that are more likely to significantly affect the firm's operational performance or financial health [8], and which are therefore more important to investors.

Studies have also shown that whereas more and more rating agencies are assessing firms' ESG performance, the assessment methodologies vary across agencies $[9,10]$. Further- 
more, to our knowledge, except Truvalue Labs [11], no rating agency to date has applied a methodology that is specifically developed to consider the financial materiality of ESG risks and opportunities. We contend that considering financial materiality in ESG assessment would allow distinguishing between firms that address substantial ESG issues from those that address mainly symbolic ESG issues that are not financially material to their business. Moreover, as many investors use ESG ratings $[1,5]$ that account for nonfinancially material issues, there seems to be some misalignment between investors' information needs and the ESG ratings provided by the rating agencies [8,12].

This mismatch provides the motivation for our study and gives rise to the following research question: would ESG ratings differ if the rating agencies considered the Sustainability Accounting Standard Board's (SASB's) ESG financial materiality framework? If so, which ESG issues would be responsible for the differences in scores?

To examine this question, we conducted a comparative analysis between the ESG performance scores assigned to firms by Morgan Stanley Capital International (MSCI) (hereafter, MSCI scores) and the scores adjusted according to the Sustainability Accounting Standard Board's (SASB) financial materiality framework (hereafter, SASB-adjusted scores). Our final sample comprised 497 US public-listed firms operating in three different industry sectors: Materials (137), Consumer Staples (99), and Consumer Discretionary (261). We adopted an empirical research design to examine the effect of applying SASB's financial materiality framework to the firms' ESG rankings. This allowed determining the extent of misalignment between ESG assessments by rating agencies and ESG information that, according to SASB, is material and more relevant to investor decisions.

Our results revealed that the SASB-adjusted scores for our sample firms differed from the original MSCI scores and were generally lower across all three sectors. Moreover, the differences were statistically significant for two of the three sectors. The results also showed that, after SASB adjustment, the scores for environmental issues showed a significant downward trend for all three sectors, providing the main explanation for the differences between the original MSCI scores and the SASB-adjusted scores. More specifically, of the environmental pillar issues, the scores for Natural resource use declined the most. Overall, from $28 \%$ to $74 \%$ of the firms underwent a change in ranking of at least one quartile, depending on the sector, the most affected sector being Consumer Staples.

This study contributes to the literature on ESG performance assessment in several ways. First, by examining the effect of the application of SASB's financial materiality framework to rate and rank firms' ESG performance, we provide relevant insights into the relationships between ESG risks and financial performance. This contributes to the ongoing discussion on the relevance of ESG information provided by rating agencies. ESG information is critical so that investors can conduct risk analyses and assess the likely impacts on firms' profitability, and hence determine firms' cost of capital $[5,13,14]$.; In support of this argument, a review by Clark et al. [15] showed that $90 \%$ of 29 empirical studies conclude that better ESG practices reduce companies' cost of capital, and that $88 \%$ of 51 studies found a positive correlation between ESG performance and operational performance. Our results therefore challenge the informative nature of currently used ESG ratings. We contend that the assessment of nonfinancially material ESG issues can bias ESG-based investment decisions. Furthermore, our results indicate that firms can use a financial materiality framework to prepare more effective and coherent ESG disclosures that better meet the information needs of capital markets.

Second, our examination of the effect of financial materiality on firms' ESG ratings and rankings built on and extended the importance of integrating financial materiality in investment practices and calls for the establishment of appropriate benchmarks of ESG performance. Our results showed significant differences between original MSCI ESG scores and scores adjusted for financial materiality for our sample firms. We interpret this as evidence that investors who use these scores to evaluate their investment portfolios could reach different conclusions (e.g., determine different portfolio evaluations). In other words, we contend that the SASB-adjusted score allows investors to better differentiate 
between firms who score highly on ESG issues that are financially material to their business (business-critical ESG issues), from firms who score highly on issues that are not financially material to their business. Because investment practices are deeply rooted in the financial logic of shareholder value, despite of its social and environmental goals, our evidence corroborates the evidence that integrating financial materiality in ESG scores can better inform investment decisions based on ESG performance [16]. Hence, our study also contributes to the development of improved measures for both ESG disclosure quality and ESG performance assessment. Thus, our results support the argument that innovations in accounting standardization practices, such as the ESG disclosure standards proposed by SASB, can guide researchers and practitioners to develop more relevant ESG disclosure tools [8].

Third, this study makes a significant practical contribution in terms of the methodology. More precisely, we establish useful correspondences between two industry classification schemes: the Sustainable Industry Classification System (SICS) developed by SASB and the more standard Global Industry Classification Standards (GICS). This knowledge can aid researchers in future studies and help investors determine the effects of considering industry-specific materiality for ESG performance assessments. A further significant contribution is the matching of financially material ESG issues according to SASB and the ESG issues assessed by MSCI ESG Ratings. This proposed equivalence could help investors, lenders and credit analysts target the information they need to more accurately assess stock prices as well as ESG risks and opportunities.

The next section describes the role of financial materiality in ESG performance assessment. The data collection and research methods are then described, followed by the results and discussion. The final section summarizes the findings and contributions.

\section{ESG Information and Financial Materiality}

ESG information disclosure remains mainly voluntary, and publicly listed firms can choose from a variety of regulatory filings to disclose their ESG information. This adversely affects access by investors who wish to assess a firms' ESG performance to make investment decisions. Furthermore, whereas some regulatory filings, such as annual financial reports, are subject to independent audits, this does not apply to all regulatory filings. Studies have also demonstrated that publicly available ESG information does not necessarily meet investors' needs $[17,18]$. This information gap is driven not only by firms' varying degrees of compliance with ESG disclosure requirements, but also by issuers' discretionary interpretations of material information. This can result in the omission of ESG-related information from regulatory filings [8]. At the same time, studies show that firms are increasingly reporting on ESG factors $[5,19]$ and that disclosures are higher in countries with stronger nation-level institutions [20].

For instance, signatories to the Principles for Responsible Investment (PRI), launched in 2006 by the United Nations, committed to incorporate these principles in their investing practices to develop a more sustainable global financial system. As of 2020, the number of signatories had grown from 100 to over 3000, with total managed assets of about $\$ 100$ trillion [21].

Some companies choose to publish a social responsibility report (CSR), while others publish a sustainable development report according to Global Reporting Initiative (GRI) standards or an integrated report in line with the International Integrated Reporting Council (IIRC).

We used the ESG disclosure framework proposed by the Sustainability Accounting Standards Board (SASB) for our analysis. SASB advocates the financial materiality of ESG issues, in other words, the potential effects of ESG issues on investment value. It is important to clarify that SASB's financial materiality framework was developed to enable companies to identify, manage and communicate material ESG information to their investors in a consistent, comparable and reliable manner. Furthermore, because industries determine their own financially material issues, the SASB classification allows 
comparison of firms within a same industry. According to Schiehll and Kolahgar [8] and Grewal et al. [22], firms that provide more SASB-identified sustainability disclosure have higher stock price informativeness, suggesting that this type of disclosure contains more financially relevant, firm-specific information. Similarly, Brulhart and Gherra [23] showed that greater transparency and selective attention paid to stakeholders (i.e., prioritization of a small range of primary stakeholders) has a positive effect on firms' profitability.

The SASB's definition of materiality is the same as that used by the Securities and Exchange Commission (SEC). In the case of TSC Industries, Inc. v. Northway Inc., the Supreme Court of the United States interprets materiality as follows:

According to the U.S. Supreme Court, a fact is material if, in the event such fact is omitted from a particular disclosure, there is "a substantial likelihood that the disclosure of the omitted fact would have been viewed by the reasonable investor as having significantly altered the 'total mix' of the information made available." (TSC Industries, Inc. v. Northway Inc., 426 US 438, 449, 1976) [24].

Furthermore, the SASB framework classifies ESG issues into five (5) dimensions (Environment, Social Capital, Human Capital, Business Model and Innovation, Leadership, and Governance) and twenty-six (26) general issue categories [25]. More importantly, SASB identifies issues that are financially material for each sector and their respective industries, using a tool called the SASB Materiality Map ${ }^{\circledR}$. Because ESG issues (including the risks and opportunities) often manifest in unique ways for specific business models, industry specificity is critical for assessing the financial materiality of environmental and social issues [8], and consequently for assessing firms' ESG performance. Therefore, SASB mapping offers a third, independent framework to identify the ESG issues that are more likely to affect a firm's financial condition or operating performance in the industry in which the focal firm operates. The SASB mapping process is described in greater detail in the following section. Immediately below, we present the research methods we use to examine whether considering financial materiality in ESG performance assessments produces different ESG scores for the sample firms.

\section{Research Methods}

\subsection{ESG Ratings}

In parallel with the recent and growing demand for ESG information, the number of rating agencies that provide ESG information and assessments has grown significantly. According to Kumar and Weiner [26], at least 125 rating agencies performed ESG performance assessments in 2016. However, each agency uses its own methodology and criteria to determine the materiality of ESG issues. Consequently, ratings for a same company could vary across agencies. For instance, Kumar and Weiner [26] determined that MSCI and Sustainalytics, two of the most widely used rating agencies, had a correlation of only 0.53 between their ESG scores. Similarly, Chatterji et al. [9] obtained correlations between scores as low as 0.3 . This indicates that the choice of rating agency could have a considerable impact on ESG scores and rankings, and consequently on investors' decisions.

Given the availability of data, we used the MSCI rating system for purposes of our analysis. More specifically, we consulted the MSCI ESG Ratings database. MSCI is a primary source of ESG information [26]. According to an MSCI report (2018) on responsible investing trends, more than \$US 108 billion in financial funds were rated with the MSCI ESG indices in 2017. The ESG indices generated 30\% more profit for MSCI in 2018 than in 2017 [27]. The MSCI ESG Ratings system provides information on 37 ESG key issues concerning over 7000 companies in over 30 countries. A score of 0 to 10 is assigned for each ESG key issue deemed material for an industry. Scores are determined based on the firm's risk exposure and risk management. A weight is assigned to the issue according to its contribution to environmental and social impacts. The scores and weights for each ESG key issue are then grouped into ten themes. These themes are associated with one of the three ESG pillars (environmental, social and governance issues) to produce the weighted average ESG score. The weighted average scores are subsequently normalized to the industry level 
to obtain the industry-adjusted average score (0 to 10$)$. Finally, the industry-adjusted score is used to assign a lettered score to the firm ranging from AAA (best) to CCC (worst) in terms of ESG performance [28].

The MSCI ESG Ratings system uses the Global Industry Classification Standards (GICS). These standards cover 11 sectors broken down into 24 industry groups, 69 industries, and 158 subindustries. Each of the 158 subindustries is subject to a materiality assessment process. Subindustries with similar material issues are classified as ESG industries to facilitate comparisons [29]. According to MSCI's methodology, an issue is considered to be material to an industry when it is likely that companies in a given industry will incur substantial costs in connection with it [28]. All the corporate governance issues are assessed for all firms. Thus, the MSCI ESG materiality criteria differ from those for SASB, which concern financially material issues that are reasonably likely to impact a firm's financial situation or operating performance. Therefore, the SASB criteria are better aligned with investors' information needs [8,12].

\subsection{Sample}

The starting point for our sample was the MSCI ESG Ratings database. The year 2018 was chosen, given the availability of the information (MSCI scores) and our aim was to perform an analysis that reflects the current situation as far as possible. We focused on firms operating in the United States (observation "US" for the variable Home market). The objective was to ensure comparability by analyzing firms that operate under similar market pressure concerning ESG issues and similar regulations. This brought the target sample to 2659 US firms.

\subsection{Selected Sectors and SASB Equivalents}

Because the analysis and comparison of ESG scores and financially material issues should be done within a sector or industry, our next step was to choose the sectors to analyze. Three sectors (according to the MSCI/GICS classification) were selected, based on two main criteria. First, we aimed to select sectors including industries exposed to many and diversified ESG risks and opportunities, in both social and environmental respects to provide a meaningful representation of financially material and nonmaterial issues. This explains why sectors such as Finance and Communications, which present relatively few environmental issues, were not selected. Thus, we targeted major sectors including several and important industries and subindustries, as shown in the Supplemental Material, Tables S1-S3. Second, we wanted to include a significant number of firms, to assure that our sample was representative of the MSCI ESG ratings universe. Hence, we targeted the nonfinancial sectors contained in the MSCI database with the largest number of U.S. firms. Accordingly, we chose the following three sectors: Materials, Consumer Staples and Consumer Discretionary Products, resulting in a sample of 137, 105 and 279 firms operating in these three sectors, respectively. Table 1 presents the distribution per sector and shows that our final sample of 521 firms represented $28 \%$ of all U.S. public listed firms included in the MSCI ESG ratings dataset. In Table 2, the cells in gray identify the ESG issues identified by the SASB framework as financial material. This table shows that the three sectors represented in our final sample covered 24 out of 26 General Issue Categories comprised in the SASB Materiality Map.

Table 1. Final sample distribution per sector.

\begin{tabular}{lcc}
\hline \multicolumn{1}{c}{ Sector } & Number of U.S. Firms & Percentage (\%) \\
\hline Materials & 137 & $7 \%$ \\
Consumer Staples & 105 & $6 \%$ \\
Consumer Discretionary & 279 & $15 \%$ \\
Sample size & 521 & $28 \%$ \\
Other nonfinancial sectors in the MSCI ESG & 1337 & $72 \%$ \\
Ratings Dataset & 1858 & $100 \%$ \\
Total & & \\
\hline
\end{tabular}


Table 2. Sustainability Accounting Standard Board (SASB) Materiality Map ${ }^{\circledR}$ environmental, social and governance (ESG) issues covered by the final sample.

\begin{tabular}{|c|c|c|c|c|}
\hline SASB Dimension & $\begin{array}{c}\text { SASB } \\
\text { General Issue Categories }\end{array}$ & $\begin{array}{c}\text { Consumer } \\
\text { Discretionary }\end{array}$ & $\begin{array}{l}\text { Consumer } \\
\text { Staples }\end{array}$ & Materials \\
\hline Environment & $\begin{array}{c}\text { GHG Emissions } \\
\text { Air Quality } \\
\text { Energy Management } \\
\text { Water \& Wastewater Management } \\
\text { Waste \& Hazardous Materials Management } \\
\text { Ecological Impacts }\end{array}$ & & & \\
\hline Social Capital & $\begin{array}{c}\text { Human Rights \& Community Relations } \\
\text { Customer Privacy } \\
\text { Data Security } \\
\text { Access \& Affordability } \\
\text { Product Quality \& Safety } \\
\text { Customer Welfare } \\
\text { Selling Practices \& Product Labeling }\end{array}$ & & & \\
\hline Human Capital & $\begin{array}{c}\text { Labor Practices } \\
\text { Employee Health \& Safety } \\
\text { Employee Engagement, Diversity \& Inclusion }\end{array}$ & & & \\
\hline $\begin{array}{l}\text { Business Model \& } \\
\text { Innovation }\end{array}$ & $\begin{array}{c}\text { Product Design \& Lifecycle Management } \\
\text { Business Model Resilience } \\
\text { Supply Chain Management } \\
\text { Materials Sourcing \& Efficiency } \\
\text { Physical Impacts of Climate Change }\end{array}$ & & & \\
\hline $\begin{array}{l}\text { Leadership \& } \\
\text { Governance }\end{array}$ & $\begin{array}{c}\text { Business Ethics } \\
\text { Competitive Behavior } \\
\text { Management of the Legal \& Regulatory Environment } \\
\text { Critical Incident Risk Management } \\
\text { Systemic Risk Management }\end{array}$ & & & \\
\hline
\end{tabular}

The next step was to establish a correspondence between the industry classification used by the MSCI ESG Ratings, the GICS system, and the industry classification proposed by the SASB's financial materiality framework, the SICS system, for each subindustry in the three sectors. Table 3 presents a summary comparison of the GICS and SICS industry classifications. This step allowed applying the SASB Materiality Map ${ }^{\circledR}[30]$ to the sample firms and industries, also called SASB mapping. The SASB mapping is based on series of materiality tests, the results of which were ultimately debated and validated by industry working groups composed of industry experts. Basically, the materiality tests have three components: evidence of interest, evidence of financial impact and forward impact adjustments [7]. Hence, we conducted a descriptive analysis at the industry- and subindustry level and then compared the two ratings systems. A detailed description is provided in the Supplemental Material, Table S4.

Table 3. Summary comparison of Global Industry Classification Standards (GICS) and Sustainable Industry Classification Standards (SICS) industry classifications.

GICS-Global Industry Classification Standards [29]

11 Sectors

24 Industry groups

69 Industries

158 Sub-industries
SICS-Sustainable Industry Classification System [31]

11 Sectors

38 Sub-sectors

77 Industries

Note that whereas the MSCI ESG Ratings system uses the GICS classification, it groups together certain subindustries with similar ESG issues to form ESG industries. Therefore, 
some firms are classified as ESG industries in the MSCI ESG ratings database. Thus, after establishing equivalence with the SASB classification for the three sectors, some ESG industries are made up of subindustries that involve different types of ESG risks. These ESG industries are Diversified Consumer Services, Hotels and Travel, Household Durables, Retail-Consumer Discretionary, Beverages, Food Products, Retail-Food \& Staples, and Paper and Forest Products.

To perform a consistent comparative analysis, the sample firms that were MSCI-classified as ESG industries were identified manually and individually by their names using the SICS Look-up Tool available on the SASB website [31]. The objective was to obtain a more precise correspondence between the SASB SICS classification and the respective SASB Materiality Map $^{\circledR}$ for these firms. However, some firms could not be found with this search tool, and for others the industry classification provided by SASB (SIC system) were significantly different from the original industry classification used by MSCI (GICS system). Therefore, these firms $(n=24)$ were excluded from the final sample. The final sample comprised 137 firms from the Materials sector, 99 from the Consumer Staples sector and 261 from the Consumer Discretionary sector.

\subsection{Matching MSCI's ESG Key Issues Using SASB Mapping}

In this step we established the correspondence between the ESG issues and data items assessed by the MSCI ESG Ratings system and the financially material issues identified by SASB. Table 4 presents an overview comparison between the MSCI and SASB classifications.

Table 4. Summary comparison of Morgan Stanley Capital International MSCI and SASB components.

\begin{tabular}{cc}
\hline MSCI ESG Ratings [28] & SASB [30] \\
\hline 3 Pillars & 3 Pillars \\
10 Themes & 5 Dimensions \\
37 ESG Key Issues & 26 ESG General Issues Categories \\
\hline
\end{tabular}

To do so, we analyzed each described issue to establish correspondence between the 37 MSCI-determined ESG key issues and the 26 SASB-determined ESG general issue categories. The governance pillar issues were difficult to reconcile due to significant variations in definitions and applicability. For example, the MSCI ESG Ratings system consistently considers corporate governance issues as material for all industries, whereas they are considered industry-sensitive according to the SASB materiality framework. We therefore excluded governance issues (i.e., the governance pillar) from our comparative analysis and considered them as material, as assessed in the original MSCI ESG score. Thus, the remainder of our comparative analysis focused on the environmental (E) and social (S) pillars and their respective scores. It is also worth noting that four MSCI-assessed issues, Financing Environmental Impact, Product Safety and Quality, Responsible Investment, and Insuring Health and Demographic Risk, do not have equivalence with SASB's general issue categories. Adopting a conservative position, we considered all these issues as financially material. We therefore retained their MSCI scores to calculate the SASB-adjusted score. However, as it turns out, only a few firms in the sample were scored on these issues, so the impact at this level was negligible. The Supplemental Material (Tables S1-S4) presents the correspondence map between the MSCI and SASB ESG issues.

The next step was to apply SASB mapping to the issues included in the MSCI ESG scores. To do so, we matched the issues that SASB determines as financially material, according to their (industry-specific) materiality framework, with the equivalent ESG issues assessed by MSCI. In this process, we used the SASB Materiality Map ${ }^{\circledR}$ and the maps for equivalent issues and industry classifications. Figure 1 summarizes the matching process. 


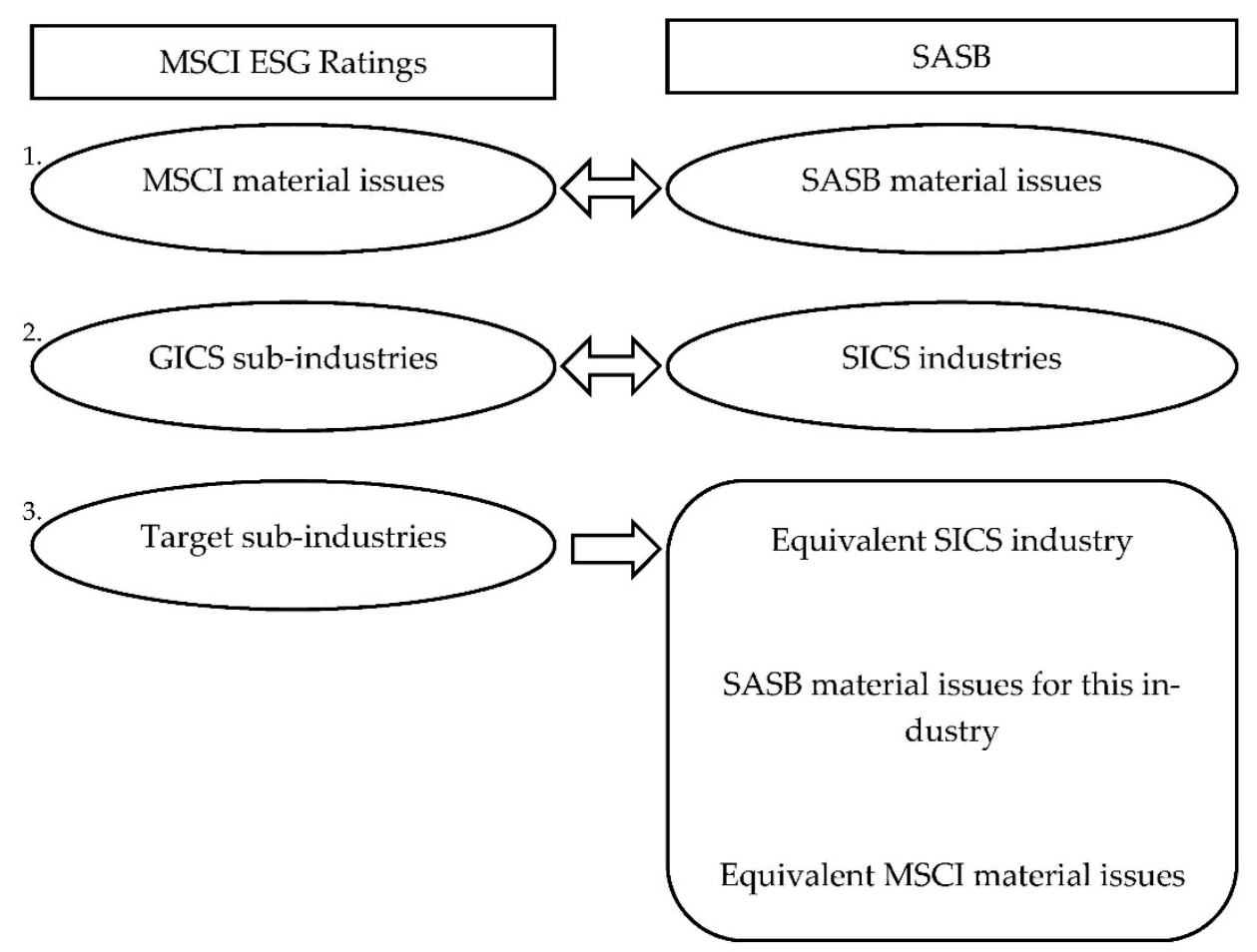

Figure 1. Correspondence process between MSCI and SASB.

\subsection{The SASB-Adjusted ESG Score}

In this section, we describe the steps in calculating the SASB-adjusted scores for the sample firms. The social and environmental issues that were initially included in the ESG MSCI scores but were subsequently determined as nonfinancially material after SASB mapping were excluded from the calculation. SASB mapping was applied to each industry in the sample. For purposes of objectivity, SASB-identified material issues that were not assessed in the MSCI dataset were not scored or weighted. In sum, the SASB-adjusted scores were based on financially material issues that were also assessed in the MSCI ESG Ratings database for the year under analysis (2018). As explained above, the MSCI scores for issues that did not obtain equivalence after SASB mapping (i.e., Financing of Environmental Impact, Product Safety and Quality, Responsible Investment, and Insuring Health and Demographic Risk) and for governance issues were kept in the SASB-adjusted ESG score as originally assessed by MSCI. We therefore adopted a conservative approach to calculate the SASB-adjusted score.

MSCI's methodology is designed such that the weights assigned to each of the three pillars must add up to $100 \%$. To retain this criterion, we established that when a nonmaterial issue was removed to calculate the SASB-adjusted score, its weight was distributed proportionately to the remaining financially material issues under the same theme. If an entire MSCI theme (see Table 4) was removed from the calculation, its weight was distributed proportionately among the other themes in the same pillar (social or environmental). If all the assessed issues in a pillar were removed from the calculation, then the weight of this pillar was redistributed between the two remaining pillars (environmental, social or governance).

Note that the scores for issues remained the same as originally calculated and reported by MSCI. What differs here are the scores for the themes, the scores for the pillars (social and environmental) and the weighted average scores, which were recalculated to account for the newly assigned weights and/or removed for certain issues identified as nonfinancially material by SASB.

Mathematical tests were performed to reproduce the formulae that the MSCI ESG Ratings system uses to obtain its scores. The same formulae were then used to calculate the SASB-adjusted scores, as presented below: 
- The formula used to calculate the score for an ESG issue theme:

$((\mathrm{I} 1 * \mathrm{~W} 1) /(\mathrm{W} 1+\mathrm{W} 2+\ldots+\mathrm{W} i))+\left(\left(\mathrm{I} 2^{*} \mathrm{~W} 2\right) /(\mathrm{WI}+\mathrm{W} 2+\ldots+\mathrm{W} i)\right)+\ldots+\left(\left(\mathrm{I} i^{*} \mathrm{~W} i\right) /(\mathrm{W} 1\right.$ $+\mathrm{W} 2+\ldots+\mathrm{Wi}))$

where $\mathrm{I} i=$ Score for issue $i$ in the theme; and

$\mathrm{W} i=$ Weight for issue $i$ in the theme

- The formula used to calculate the score for a pillar corresponds to: $\left(\left(\mathrm{T} 1{ }^{*} \mathrm{~W} 1\right) /(\mathrm{W} 1+\mathrm{W} 2\right.$ $+\ldots+\mathrm{W} i))+\left(\left(\mathrm{T} 2^{*} \mathrm{~W} 2\right) /(\mathrm{W} 1+\mathrm{W} 2+\ldots+\mathrm{W} i)\right)+\ldots+\left(\left(\mathrm{T} i^{*} \mathrm{~W} i\right) /(\mathrm{W} 1+\mathrm{W} 2+\ldots+\mathrm{W} i)\right)$ where $\mathrm{T} i=$ Score for theme $i$ in the pillar; and

$\mathrm{W} i=$ Weight of theme $i$ in the pillar

- The formula used to calculate the weighted average score corresponds to:

[(Environmental pillar score * Environmental pillar weight $)+($ Social pillar score * Social pillar weight $)+($ Governance pillar score * Governance pillar weight $) / 100)]$.

Table 5 below illustrates the comparison between the original MSCI score and the SASB-adjusted score, for three firms in our sample:

Table 5. Comparing the original MSCI score and the SASB-adjusted score for three sample firms.

\section{Monsanto Company (Sector: Materials)}

MSCI score $=4.1$

E-MSCI score $=4.1$

S-MSCI score $=0.5$

Pepsico Inc. (Sector: Consumer Staples)

MSCI score $=6.5$

E-MSCI score $=7.8$

S-MSCI score $=5.8$
SASB-adjusted score $=3.9$

$\left((3.9 * 50)+(0.5 * 21)+\left(3.8^{*} 29\right)\right) / 100=3.9$

E-SASB-adjusted score $=3.9$

$\left(\left(\left(10^{*} 9\right) /(9+14.1+26.9+0)\right)+((5.1 * 14.1) /(9+14.1+26.9+0))+\right.$

$\left.\left(\left(1.3^{*} 26.9\right) /(9+14.1+26.9+0)\right)+\left(\left(0^{*} 0\right) /(9+14.1+26.9+0)\right)\right)=3.9$

S-SASB-adjusted score $=0.5$

$\left(\left(\left(0^{*} 0\right) /(0+21+0+0)\right)+\left(\left(0.5^{*} 21\right) /(0+21+0+0)\right)+\right.$

$\left.\left(\left(0^{*} 0\right) /(0+21+0+0)\right)+\left(\left(0^{*} 0\right) /(0+21+0+0)\right)\right)=0.5$

Target Corporation (Sector: Consumer discretionary)

\begin{tabular}{ll}
\hline MSCI score $=4.6$ & $\begin{array}{l}\text { SASB-adjusted score }=3.9 \\
\left(\left(6.6^{*} 16\right)+\left(2.7^{*} 68\right)+\left(6.1^{*} 16\right)\right) / 100=3.9\end{array}$ \\
\hline & $\begin{array}{l}\text { E-SASB-adjusted score }=6.6 \\
=\left(\left(\left(6.6^{*} 16\right) /(16+0+0+0)\right)+\left(\left(0^{*} 0\right) /(16+0+0+0)\right)+\right. \\
\left.\left(\left(0^{*} 0\right) /(16+0+0+0)\right)+\left(\left(0^{*} 0\right) /(16+0+0+0)\right)\right)=6.6\end{array}$ \\
\hline & S-SASB-adjusted $=2.7$ \\
& $\left(\left(\left(2.4^{*} 36\right) /(36+32+0+0)\right)+\left(\left(3^{*} 32\right) /(36+32+0+0)\right)+\right.$ \\
& $\left.\left(\left(0^{*} 0\right) /(36+32+0+0)\right)+\left(\left(0^{*} 0\right) /(36+32+0+0)\right)\right)=2.7$
\end{tabular}

MSCI score is the Weighted Average score; E-MSCI score is the Environmental pillar score; and S-MSCI score is the Social pillar score.

This step was applied for all the firms according to their industry. Unfortunately, it was impossible to calculate the SASB-adjusted final lettered assessment (AAA-CCC), as in the MSCI ESG dataset. The MSCI's lettered assessment is based on the industry-adjusted score derived from external data available only from the MSCI ACWI database, which was not available for this study. Hence, we used the terms MSCI Score and SASB-adjusted score to refer to the firms' weighted average scores. The difference between the MSCI score and the SASB-adjusted represents, therefore, the effect of excluding the assessment of 
ESG issues that are not financially material for the focal firm. We contend that the score difference allows to better differentiate between firms who score highly on ESG issues that are financially material to their business, from firms who score highly on issues that are not financially material to their business. In other words, the score difference can signal to investors firms that address substantial ESG issues from those that address mainly symbolic ESG issues.

In order to validate that the differences between original MSCI scores and SASBadjusted scores (hereafter, Score Difference) were not driven by sample firms' attributes, we analyzed the correlation coefficients between the Score Difference and four firm characteristics. Firm size was measured as the natural logarithm of firm market capitalization (Size), firm growth opportunities was measured as the ratio of the market value of equity to the book value of equity (MtoB), and firm profitability was measured as the ratio of income before extraordinary items over total assets (ROA) and the ratio of income before extraordinary items over equity (ROE). We measured these variables at the end of the fiscal year (2018) and data were retrieved from Compustat. As shown in Table 6, Panels A, B and $\mathrm{C}$, overall, the correlation coefficients between Score Differences and firm attributes are not statistically significant, providing evidence along the three sectors that the differences between original ESG score and SASB-adjusted ESG score were not driven by firms' characteristics.

Table 6. Means and correlation coefficients between score difference and firms' characteristics.

\begin{tabular}{|c|c|c|c|c|c|c|}
\hline \multicolumn{7}{|c|}{ Panel A: Materials $(n=137)$ Score differences and firms' characteristics in $t(2018)$} \\
\hline Variables & Mean & (1) & (2) & (3) & (4) & (5) \\
\hline (1) Score Difference $e_{t}$ & -0.026 & 1.000 & & & & \\
\hline (2) Size $_{t}$ & 21.557 & $\begin{array}{l}-0.012 \\
(0.896)\end{array}$ & 1.000 & & & \\
\hline (3) Market-to-Bookt & 2.278 & $\begin{array}{c}0.042 \\
(0.651)\end{array}$ & $\begin{array}{l}0.194 * \\
(0.034)\end{array}$ & 1.000 & & \\
\hline (4) $\mathrm{ROA}_{\mathrm{t}}$ & 7.252 & $\begin{array}{c}0.151 \\
(0.097)\end{array}$ & $\begin{array}{l}0.239 * \\
(0.009)\end{array}$ & $\begin{array}{c}0.146 \\
(0.113)\end{array}$ & 1.000 & \\
\hline (5) $\mathrm{ROE}_{\mathrm{t}}$ & 22.045 & $\begin{array}{c}0.007 \\
(0.940)\end{array}$ & $\begin{array}{l}-0.032 \\
(0.731)\end{array}$ & $\begin{array}{c}0.112 \\
(0.232)\end{array}$ & $\begin{array}{l}0.265^{*} \\
(0.004)\end{array}$ & 1.000 \\
\hline \multicolumn{7}{|c|}{ Panel B: Consumer Staples $(n=105)$ Score differences and firms' characteristics in $t(2018)$} \\
\hline $\begin{array}{l}\text { Variables } \\
\text { (1) Score Difference }\end{array}$ & $\begin{array}{l}\text { Mean } \\
0.081\end{array}$ & $\begin{array}{c}(1) \\
1.000\end{array}$ & (2) & (3) & (4) & (5) \\
\hline (2) Size $\mathrm{S}_{\mathrm{t}}$ & 22.503 & $\begin{array}{c}0.151 \\
(0.172)\end{array}$ & 1.000 & & & \\
\hline (3) Market-to-Book & -2.381 & $\begin{array}{l}-0.100 \\
(0.369)\end{array}$ & $\begin{array}{l}-0.072 \\
(0.516)\end{array}$ & 1.000 & & \\
\hline (4) $\mathrm{ROA}_{\mathrm{t}}$ & 8.751 & $\begin{array}{l}-0.190 \\
(0.086)\end{array}$ & $\begin{array}{l}0.252 * \\
(0.022)\end{array}$ & $\begin{array}{c}0.034 \\
(0.761)\end{array}$ & 1.000 & \\
\hline (5) $\mathrm{ROE}_{\mathrm{t}}$ & 33.260 & $\begin{array}{c}0.199 \\
(0.080)\end{array}$ & $\begin{array}{c}0.221 \\
(0.051)\end{array}$ & $\begin{array}{c}-0.910 * \\
(0.000)\end{array}$ & $\begin{array}{l}0.207 \\
(0.070)\end{array}$ & 1.000 \\
\hline \multicolumn{7}{|c|}{ Panel C: Consumer Discretionary $(n=279)$ Score differences and firms' characteristics in $\mathrm{t}(2018)$} \\
\hline $\begin{array}{l}\text { Variables } \\
\text { (1) Score Difference }\end{array}$ & $\begin{array}{l}\text { Mean } \\
-0.024\end{array}$ & $\begin{array}{l}(1) \\
1.000\end{array}$ & (2) & (3) & (4) & (5) \\
\hline (2) Size $_{t}$ & 21.682 & $\begin{array}{c}-0.200 * \\
(0.002)\end{array}$ & 1.000 & & & \\
\hline (3) Market-to-Bookt & 2.733 & $\begin{array}{l}0.104 \\
(0.114)\end{array}$ & $\begin{array}{c}0.046 \\
(0.483)\end{array}$ & 1.000 & & \\
\hline (4) $\mathrm{ROA}_{t}$ & 8.191 & $\begin{array}{l}-0.113 \\
(0.086)\end{array}$ & $\begin{array}{l}0.275^{*} \\
(0.000)\end{array}$ & $\begin{array}{l}-0.161 * \\
(0.014)\end{array}$ & 1.000 & \\
\hline (5) $\mathrm{ROE}_{\mathrm{t}}$ & 37.986 & $\begin{array}{l}0.056 \\
(0.420)\end{array}$ & $\begin{array}{c}0.007 \\
(0.922)\end{array}$ & $\begin{array}{l}0.818^{*} \\
(0.000)\end{array}$ & $\begin{array}{l}0.137^{*} \\
(0.049)\end{array}$ & 1.000 \\
\hline
\end{tabular}


The next step was to group all the SASB-adjusted scores by sector in order to conduct a sectoral analysis, more specifically with respect to the Materials (GICS 15), Consumer Staples (GICS 30) and Consumer Discretionary (GICS 25) sectors.

\subsection{Comparing Firms' MSCI ESG Rankings with SASB-Adjusted ESG Rankings}

The final step in our analysis was to determine changes in rankings for the firms when SASB-adjusted scores were used. Thus, similar to Abramo et al. [32], all firms in the three sectors were ranked in terms of ESG performance (based on the weighted average score), and the MSCI rankings were compared with the SASB-adjusted rankings. These rankings were then broken down into quartiles and a variable was generated to capture movements in quartile ranking for each firm and, if applicable, the number of quartile shifts.

Results showed the range of the change values as $(-3,3)$. To further determine changes in ranking, this step was repeated using the scores for the environmental and social pillars. To obtain a consistent comparison, only firms with a score for both these pillars before and after SASB mapping were used to generate the rankings. It is worth noting that with the use of the SASB-identified materiality map, it is necessary to remove from some observations the scores for all the issues under a given pillar (environmental or social) and then distribute the weight of this pillar to the other pillars. A score for a pillar may be absent for two reasons: (1) the SASB Materiality Map®does not identify any material issue for the pillar in question; or (2) the material issues identified in the SASB Materiality Map®are not assessed by MSCI. Table 7 shows the number of firms analyzed for each sector based on the SASB-adjusted score, the environmental pillar score (E-SASB-adjusted score) and the social pillar score (S-SASB-adjusted score).

Table 7. Distribution of the number of observations included in the rankings.

\begin{tabular}{cccc}
\hline Sectors & SASB-Adjusted Score & E-SASB-Adjusted Score & S-SASB-Adjusted Score \\
\hline Materials (GICS 15) & $137 / 137$ & $134 / 137$ & $123 / 137$ \\
Consumer Staples (GICS 25) & $99 / 99$ & $93 / 99$ & $89 / 99$ \\
Consumer Discretionary (GICS 30) & $261 / 261$ & $145 / 261$ & $256 / 261$ \\
\hline
\end{tabular}

\section{Results}

This section presents the results of the comparison between firms' MSCI and SASBadjusted scores and their respective rankings. We begin with the $t$ test for mean differences between two samples. The null hypothesis states that the difference between the MSCI score and the SASB-adjusted score is zero at a certain significance level (H0: $\mathrm{X} 1-\mathrm{X} 2=0)$. Should the difference be statistically significant ( $p$-value < significance level), the alternative hypothesis is that the two scores differ $(\mathrm{H} 1: \mathrm{X} 1-\mathrm{X} 2 \neq 0)$. Two methods are available to compare the mean values of two samples: the $\mathrm{z}$ test and the $\mathrm{t}$ test. We use the paired two-tailed $\mathrm{t}$ test at $10 \%, 5 \%$, and $1 \%$ significance thresholds.

Second, to determine whether there are differences in firm rankings, Spearman's correlation test was used. The null hypothesis is that the two variables (MSCI ranking and SASB-adjusted ranking) are not correlated, meaning that there is a significant difference between firm's position within the two rankings $(\mathrm{H} 0: \mathrm{rs}=0)$. Should the null hypothesis be rejected ( $p$-value $>$ significance level), the alternative hypothesis is that the two variables show a linear relationship ( $11:$ rs $\neq 0$ ), meaning that the rankings are similar. Here, the variables are the firm's position in the two rankings. Third, we examined the frequency distribution by quartile of the variable ranking shift. This determines whether the firm's ranking changes by one, two or three quartiles. The aim was to assess the change magnitude when financial materiality (SASB-adjusted scores) was applied to the ESG rankings.

\subsection{Comparing Scores}

The results are now presented by sector (summarized in Table 8). First, we present the mean differences in the weighted average ESG scores, labeled the SASB-adjusted score 
and the MSCI score. The rankings are labeled the MSCI ranking and the SASB-adjusted ranking.

Table 8. Descriptive statistics.

\begin{tabular}{|c|c|c|c|c|c|c|c|c|c|c|}
\hline \multicolumn{11}{|c|}{ Panel A: MSCI scores and SASB-adjusted scores per sector sub-sample. } \\
\hline & & \multirow[b]{2}{*}{$\mathbf{N}$} & \multicolumn{4}{|c|}{ MSCI scores } & \multicolumn{4}{|c|}{ SASB-adjusted scores } \\
\hline & & & Mean. & MAX & MIN & Std Dev. & Mean. & MAX & MIN & Std Dev. \\
\hline \multirow{3}{*}{ Materials } & ESG score & 137 & 4147 & 7500 & 2000 & 0937 & 3985 & 7910 & 2000 & 1034 \\
\hline & Environmental pillar score & 134 & 3890 & 8900 & 0100 & 1726 & 3771 & 10,000 & 0100 & 1920 \\
\hline & Social pillar score & 123 & 3241 & 10,000 & 0000 & 1825 & 2750 & 7800 & 0000 & 1698 \\
\hline \multirow{3}{*}{$\begin{array}{l}\text { Consumer } \\
\text { Staples }\end{array}$} & ESG score & 99 & 4372 & 6500 & 1800 & 0947 & 4165 & 7470 & 1189 & 0119 \\
\hline & Environmental pillar score & 93 & 3880 & 8700 & 0000 & 2007 & 3410 & 10,000 & 0000 & 2446 \\
\hline & Social pillar score & 89 & 4298 & 6500 & 1200 & 1219 & 4255 & 8800 & 0000 & 1888 \\
\hline \multirow{3}{*}{$\begin{array}{c}\text { Consumer } \\
\text { discretionary }\end{array}$} & ESG score & 261 & 4428 & 7300 & 2100 & 1018 & 4368 & 7550 & 1.24 & 0695 \\
\hline & Environmental pillar score & 145 & 3293 & 9200 & 0300 & 1722 & 3016 & 10,000 & 0000 & 1950 \\
\hline & Social pillar score & 256 & 4077 & 8300 & 1500 & 1044 & 3991 & 7700 & 0000 & 1413 \\
\hline \multicolumn{11}{|c|}{ Panel B: T-Test for mean differences between the original MSCI scores and the SASB-adjusted scores per industry sub-sample. } \\
\hline & & $\mathbf{N}$ & MSCI & cores & SAS & $\begin{array}{l}\text {-Adjusted } \\
\text { cores }\end{array}$ & Difference & $p$-V & & $\begin{array}{c}\text { Significance } \\
£\end{array}$ \\
\hline \multirow{3}{*}{ Materials } & ESG score & 137 & \multicolumn{2}{|c|}{4147} & \multicolumn{2}{|c|}{3985} & $(0162)$ & \multicolumn{2}{|c|}{00002} & $* * *$ \\
\hline & Environmental pillar score & 134 & \multicolumn{2}{|c|}{3890} & \multicolumn{2}{|c|}{3771} & (0119) & \multicolumn{2}{|c|}{00464} & ** \\
\hline & Social pillar score & 123 & \multicolumn{2}{|c|}{3241} & \multicolumn{2}{|c|}{2,75} & $(0491)$ & \multicolumn{2}{|c|}{00004} & $* * *$ \\
\hline \multirow{3}{*}{$\begin{array}{l}\text { Consumer } \\
\text { Staples }\end{array}$} & ESG score & 99 & \multicolumn{2}{|c|}{4372} & \multicolumn{2}{|c|}{4165} & $(0207)$ & \multicolumn{2}{|c|}{00014} & $* * *$ \\
\hline & Environmental pillar score & 93 & \multicolumn{2}{|c|}{3880} & \multicolumn{2}{|c|}{3410} & (0361) & \multicolumn{2}{|c|}{00003} & $* * *$ \\
\hline & Social pillar score & 89 & \multicolumn{2}{|c|}{4298} & \multicolumn{2}{|c|}{4255} & $(0043)$ & \multicolumn{2}{|c|}{07073} & \\
\hline \multirow{3}{*}{$\begin{array}{c}\text { Consumer } \\
\text { discretionary }\end{array}$} & ESG score & 261 & \multicolumn{2}{|c|}{4428} & \multicolumn{2}{|c|}{4368} & $(0060)$ & \multicolumn{2}{|c|}{01901} & \\
\hline & Environmental pillar score & 145 & & & & 3016 & (0277) & & & $* * *$ \\
\hline & Social pillar score & 256 & & & & 3991 & $(0086)$ & & & \\
\hline
\end{tabular}

$£:{ }^{* * *} p<0.01,{ }^{* *} p<0.05,{ }^{*} p<0.1$.

\subsubsection{Materials Sector}

Table 8 shows that the mean SASB-adjusted score was lower than that for the MSCI scores (SASB-adjusted score $=3.98$; MSCI score $=4.15 ; p$-value $=0.02 \%$ ). At the $10 \%$ significance level, this was a significant difference $(0.02 \%<10 \%)$.

However, the results of Spearman's correlation test to compare the MSCI rankings with the SASB-adjusted rankings showed a strongly positive correlation coefficient $(\mathrm{rs}=0.8788)$, demonstrating significant correlation between the two rankings ( $p$-value $=0<10 \%$ ) (see Figure 2). The results on quartile ranking movement for the 137 firms in the Materials sector sub-sample showed that the great majority $(72 \%)$ remained in the same quartile, with $23 \%$ dropping by one quartile and only $4 \%$ (6 firms) dropping by two quartiles. More specifically, two of the six firms that dropped two quartiles operate in the Forestry Management industry. 


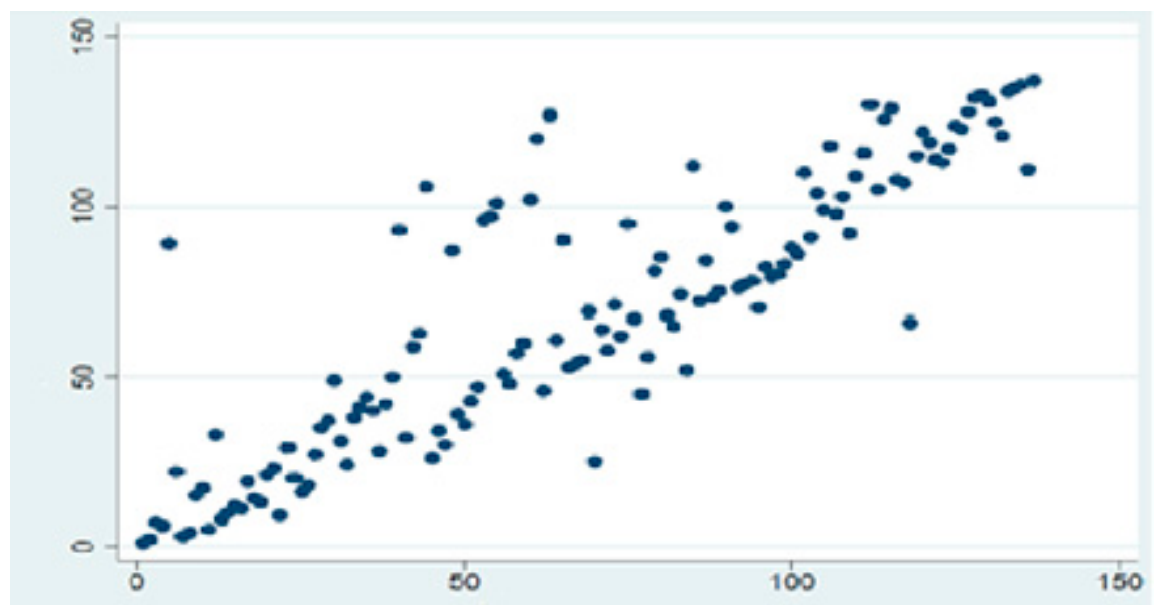

(a) Panel A, Materials, $\mathrm{r}_{\mathrm{s}}=08788$

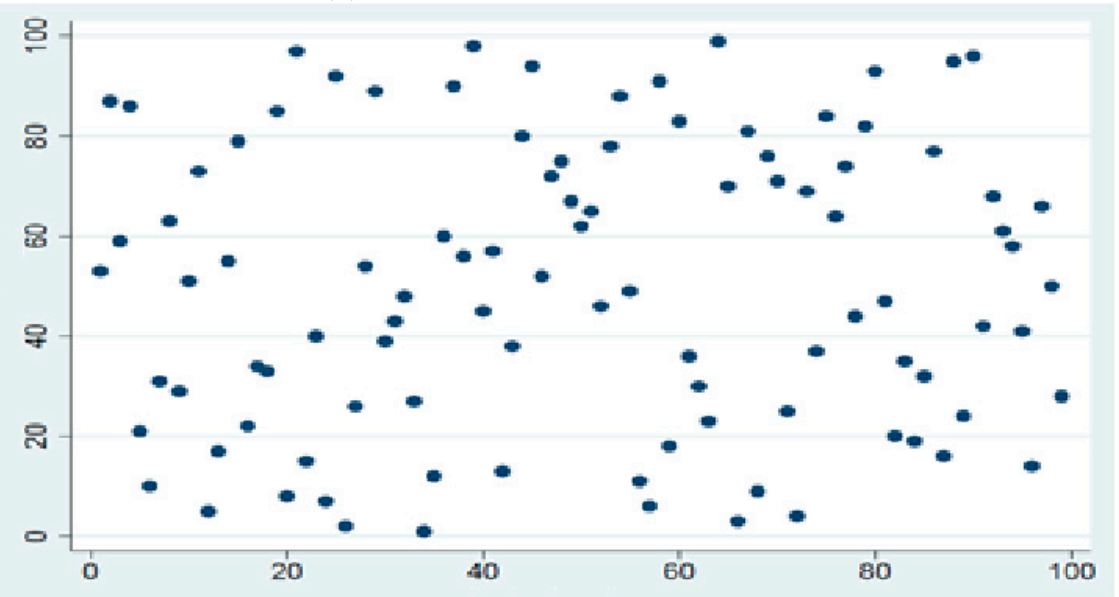

(b) Panel B, Consumer staples, $\mathrm{r}_{\mathrm{s}}=00654$

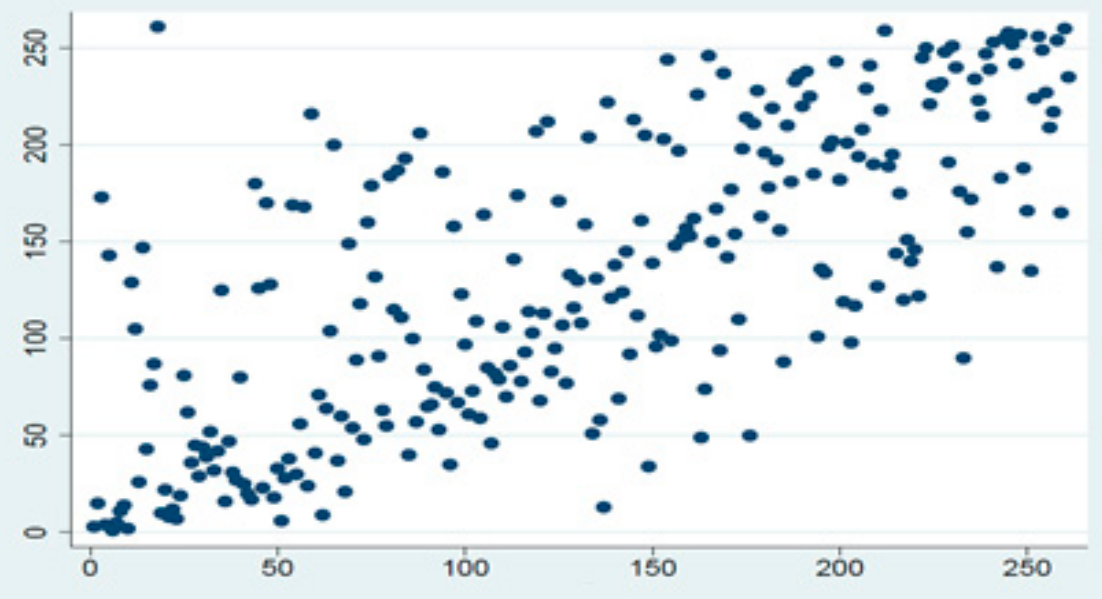

(c) Panel C, Consumer discretionary, $\mathrm{r}_{\mathrm{s}}=07187$

Figure 2. Distribution of firms' ESG rankings according to MSCI scores and SASB-adjusted scores per sector subsample.

\subsubsection{Consumer Staples Sector}

Table 8 shows that, for the Consumer Staples sector, the mean for the SASB-adjusted scores were significantly lower than those for the MSCI scores (SASB-adjusted score $=4.17$; MSCI score $=4.37 ; p$-value $=0.14 \%(<10 \%))$. This significant difference is reflected in the 
standard deviation, which is much lower for the SASB-adjusted scores. Our interpretation is that the SASB-adjusted score measured ESG performance more consistently within a same sector, and therefore generated more comparable scores. However, Spearman's comparison for the MSCI rankings and SASB-adjusted rankings obtained a very low or even nonexistent correlation coefficient ( $\mathrm{rs}=0.0654)$, indicating noncorrelation between the two rankings ( $p$-value $=52.02 \%>10 \%$ ) (see Figure 2 ). The significant difference between scores was corroborated by the results on quartile ranking movement: only $26 \%$ of the firms remained in the same quartile, while $36 \%$ shifted by one quartile, $27 \%$ by two quartiles and $10 \%$ (10 firms) by three quartiles. However, according to the SASB-adjusted scores, ten firms showed a significant movement of three quartiles: ESG ranking improved for four firms and decreased for six firms.

\subsubsection{Consumer Discretionary Sector}

For the Consumer Discretionary sector, the mean difference test also showed a lower mean SASB-adjusted score than the mean MSCI score (SASB-adjusted score $=4.37$; $\mathrm{MSCI}$ score $=4.43 ; p$-value $=19.01 \%)$. However, the difference was not statistically significant $(19.01 \%>10 \%)$ (see Table 8). Spearman's comparison between MSCI and SASB-adjusted rankings showed a positive $\left(\mathrm{r}_{\mathrm{s}}=0.7187\right)$ and significant correlation coefficient, indicating strong similarity between the two ESG rankings ( $p$-value $=0<10 \%$ ) (see Figure 2$)$. The changes in quartile ranking for the 261 firms in this sub-sample confirmed this similarity between the two rankings. A strong majority (53\%) of firms remained in the same quartile, $37 \%$ moved by one quartile, $9 \%$ ( 23 observations) moved by two quartiles, and only $1 \%$ (3 observations) moved by three quartiles. Given the nonsignificant difference between the mean MSCI score and the mean SASB-adjusted score for this sector, this small difference in quartile ranking was expected, and it corroborated the equivalence between the scores.

Overall, these results suggest that the ESG SASB-adjusted scores were lower on average for all three sectors. In two of the three sectors, Materials and Consumer Staples, this downward trend was statistically significant. This partly confirms our hypothesis that ESG performance assessment would differ when SASB mapping is applied to consider financial materiality across the environmental and social pillars.

When SASB mapping was applied to the ESG rankings, results showed that from $28 \%$ to $74 \%$ of the firms (depending on the sector) changed ranking by at least one quartile. This supports our hypothesis that applying SASB mapping to assess ESG performance could impact ESG performance rankings. In particular, the Consumer Staples sector showed a very low correlation coefficient of 0.0654 between the MSCI and SASB-adjusted rankings ( $p$-value $=0.5202)$. In addition, only $26 \%$ of observations in the Consumer Staples sector remained in the same ranking quartile. Interestingly, we note that the Materials sector retained a fairly similar ranking $(r s=0.8788)$ after SASB mapping, whereas the mean difference between the MSCI and SASB-adjusted scores was statistically significant (at 10\% significance). This could be explained by the fact that the SASB-adjusted scores for most of the firms decreased significantly in the same manner, thereby retaining similar ranking.

We conducted a deeper analysis to identify factors that could explain the differences between the MSCI and SASB-adjusted scores. Thus, we examined the social and environmental pillars separately and in greater detail to determine the effects of SASB mapping on the ESG performance assessment.

\subsection{Comparing Scores for the Environmental Pillar \\ 4.2.1. Materials Sector}

As presented above, the Materials sector subsample showed a significant difference between the MSCI scores and the SASB-adjusted scores. Therefore, we examined the potential role of the environmental pillar in this effect. The original environmental pillar scores are called E-MSCI scores. After SASB mapping, 134 of the 137 observations in this subsample still had environmental scores, called E-SASB-adjusted scores. 
Furthermore, the mean E-SASB-adjusted score for the 134 observations was lower than the mean E-MSCI score, with a significant drop (E-SASB-adjusted score $=3.77$; E-MSCI score $=3.89 ; p$-value $=4.64 \%(<10 \%))$. However, for the environmental pillar, only $17 \%$ of observations were reclassified into a different quartile, including 3\% (four observations) that decreased by two quartiles. In line with the results on the SASB-adjusted scores, these changes concerned SASB's Forestry Management industry. Moreover, Spearman's test showed a very strong correlation $(r s=0.9073$; $p$-value $=0)$ between the E-SASB-adjusted scores and E-MSCI scores.

In a closer examination of the environmental themes to explain these significant differences for the environmental pillar, the Natural Resource Use theme emerged as a factor. Of the 127 observations that had a score for this theme, 121 remained with a score after SASB mapping. The mean for SASB-adjusted scores was lower than that for MSCI scores for these 121 observations, with a significant difference (SASB-adjusted score = 4.02; MSCI score $=4.23 ; p$-value $=0.08 \%(<10 \%))$. We identified that this difference was due to the ESG key issues Biodiversity \& Land Use and Raw Material Sourcing, which are not financially material according to the SASB materiality framework. This supports the argument that the consideration of financial materiality can better inform ESG-based investment decisions.

\subsubsection{Consumer Staples Sector}

As presented above, the Consumer Staples sector also showed a significant difference between MSCI and SASB-adjusted scores. Of the 99 observations in the sub-sample, 93 had an environmental pillar score after SASB mapping. For these 93 observations, the mean ESASB-adjusted score was lower than the mean E-MSCI score, with a significant downward trend $($ E-SASB-adjusted $=3.41 ;$ E-MSCI score $=3.88 ; p$-value $=0.03 \%(<10 \%)$ ). The quartile ranking analysis of the environmental scores showed that $39 \%$ of observations in the subsample were reclassified by one quartile and $5 \%$ (five observations) by two quartiles. Of the five observations, three that dropped in ranking by two quartiles fell under SASB's Household \& Personal Products industry classification. Moreover, Spearman's test showed a strong correlation ( $\mathrm{rs}=0.8359$; $p$-value $=0)$.

These results suggest that the environmental themes do not explain this significant difference: none of them showed a significant difference in scores. This could be explained by the impact of nonfinancially material issues, the scores for which were eliminated after SASB mapping. In particular, the number of scores for Natural Resource Use decreased from 95 to 52 after SASB mapping, resulting in a significantly lower mean E-SASB-adjusted score (E-SASB-adjusted score $=3.27$; MSCI score $=4.14 ; p$-value $=0.62 \%(<10 \%)$ ) compared to the mean for the 95 original E-MSCI scores. The significant decrease in observations with a score for this theme was mainly due to the ESG key issue Raw Material Sourcing as assessed by MSCI, but which SASB considers as nonmaterial for 22 observations classified under the Household \& Personal Products industry in the Consumer Goods sector. This confirms that adjusting the ESG scores for nonfinancially material issues can improve the informativeness for ESG-based investment decisions.

\subsubsection{Consumer Discretionary Sector}

Although a nonsignificant change between the MSCI score and the SASB-adjusted score was observed for the Consumer Discretionary sector subsample, we wanted to examine whether this was also the case for its environmental and social pillars. Of the 261 observations in the sub-sample, 145 retained an environmental pillar score after SASB mapping. For these 145 observations, the mean E-SASB-adjusted score was lower than that for the mean E-MSCI score, and this difference was significant (E-SASB-adjusted score = 3.29 ; $\mathrm{E}-\mathrm{MSCI}$ score $=3.02 ; p$-value $=0.23 \%(<10 \%)$ ).

To explain this significant difference in the environmental pillar scores, an analysis of the environmental themes assessed by MSCI for this sector was performed. The results indicated no significant differences in scores. Nevertheless, we must take into consideration 
that the environmental theme scores were removed from many observations after SASB mapping. For instance, the Climate Change theme declined from scores for 261 observations (mean of 4.61) to scores for 81 observations (mean of 2.88) after SASB mapping. This substantial decrease was due to the ESG key issues Carbon Emissions and Product Carbon Footprint, which SASB considers nonfinancially material for several industries in this sector. Moreover, the Natural Resource Use theme dropped from 180 observations (mean of 4.36) to 63 observations (mean 3.5). This time the decrease was mainly attributable to the ESG key issue Raw Materials Sourcing, again considered as nonfinancially material by SASB for several industries in this sector. The elimination of these scores from the two themes appears to exert a significant upward impact on the environmental pillar score, with a significant difference between the mean E-MSCI and the mean E-SASB-adjusted scores ( $p$-value of $0 \%$ and $0.2 \%$, respectively, $<10 \%$ ).

Nevertheless, the significant difference observed for the environmental pillar was insufficient to cause a significant difference in the firms' overall ESG score (weighted average) in our sub-sample for this sector. This could be explained by the fact that, of the initial 261 observations, only 145 retained a score for the environmental pillar after SASB mapping. This acted to reduce the impact of this pillar on the overall ESG score. More precisely, if we analyze the movement in ranking quartiles for the environmental pillar scores, we note that $39 \%$ of observations differed by one quartile, with $3 \%$ (four observations) shifting by two or three quartiles. Of these four observations, three (one increase and two decreases) belonged to Apparel, Accessories \& Footwear industry. Spearman's test established a strong correlation at this level ( $r s=0.8345 ; p$-value $=0$ ).

We therefore infer that the overall ESG score was significantly impacted by the financial materiality of the environmental pillar within the sector, as specified by the SASB materiality framework. In short, in the three examined sectors, we observed a significant difference between the E-SASB-adjusted scores and the original E-MSCI scores. The themes that appeared to cause most of these differences were Climate Change and Natural Resource Use. More specifically, the ESG key issues Biodiversity \& Land Use, Raw Material Sourcing, Carbon Emissions, and Product Carbon Footprint were the main culprits. Overall, the evidence indicates that the financial (or nonfinancial) materiality of environmental pillar issues allows to better identify firms that perform well on business-critical ESG issues.

\subsection{Comparing Scores for the Social Pillar}

To complete our analysis, we also conducted a comparison of the scores for the social pillar, which showed several changes after SASB mapping. The original scores for the social pillar are referred to as S-MSCI scores and the new scores (SASB-identified materiality score) are referred to as S-SASB-adjusted scores.

\subsubsection{Materials Sector}

Again, the objective was to verify whether, in addition to the environmental pillar, the social pillar could also be responsible for the significant changes in the ESG score for this sector. Of the 137 firms in this subsample, 123 had scores on the social pillar after SASB mapping. The mean S-SASB adjusted score for these 123 firms was significantly lower than the mean S-MSCI score (S-SASB-adjusted score $=2.75$; S-MSCI score $=3.24 ; p$-value $=0,04 \%$ $(<10 \%))$. The movement in quartile ranking based on social pillar scores showed that $33 \%$ of the observations dropped by one quartile and $4 \%$ (six firms) by two or three quartiles. Of these six observations, two each belonged to Chemicals, Containers and Packaging, and Iron and Steel Producers industries. Spearman's test established a strong correlation for the social rankings $(\mathrm{rs}=0.7889 ; p$-value $=0)$.

More specifically, the Human Capital theme appeared to cause the main impact. Whereas 100 firms initially had a score for this theme, only 42 remained with a score after SASB mapping of the social pillar. This significant decrease was due to the ESG key issues Labor Management and Health and Safety, which were assessed by MSCI but are considered nonfinancially material by SASB for several industries in this sector. As 
a result, the mean S-SASB-adjusted score for the Human Capital theme for the 42 firms was lower and significantly different (S-SASB-adjusted score $=3.94$; S-MSCI score $=4.36$; $p$-value $=0.17 \%(<10 \%))$.

\subsubsection{Consumer Staples}

For the Consumer Staples sector, 89 of the 99 observations in this subsample remained with a score for the social pillar after SASB mapping. The mean S-SASB-adjusted score for these 89 firms was lower than the mean S-MSCI score, but not significantly different $(\mathrm{S}-\mathrm{SASB}$-adjusted score $=4.26$; S-MSCI score $=4.30 ; p$-value $=70.73 \%(>10 \%)$ ).

In terms of quartile ranking movement based on the social pillar scores, $28 \%$ of the 89 firms repositioned themselves by one quartile and $5 \%$ (four firms) by two or three quartiles. Of these four firms, two belonged to the Processed Foods industry. In addition, none of the social themes showed a significant difference in scores. Spearman's test established a strong correlation between the rankings based on the social pillar scores ( $\mathrm{rs}=0.8460$; $p$-value $=0$ ). We interpret this result as evidence that the environmental pillar was the most influential factor in the significant change in overall ESG scores (MSCI scores vs. SASB-adjusted scores) for this sector, which corroborates the arguments advanced by Boffo and Patalano (2020). As shown above, the environmental pillar for this sector subsample showed a significant difference in both scores and rankings ( $44 \%$ of observations were reclassified into a different quartile).

\subsubsection{Consumer Discretionary Sector}

For the Consumer Discretionary sector, 256 of the 261 observations in this subsample remained with a score for the social pillar after SASB mapping. The mean S-SASB-adjusted score for these 256 observations was lower than the mean S-MSCI scores, but this difference was not statistically significant (S-SASB-adjusted score $=3.99$; S-MSCI score $=4.08$; $p$-value $=17.73 \%(>10 \%)$ ).

However, looking at the social themes for this sector, it appears that the Human Capital theme, which showed 202 scores after SASB mapping compared to the original 258 , presented a significant difference in the mean scores (S-SASB-adjusted score $=4.50$; S-MSCI score $=4.67 ; p$-value $=8.72 \%(<10 \%))$. This could be largely explained by the ESG key issues Labor Management and Supply Chain Labor Standards, which MSCI assesses for most observations but which SASB considers nonfinancially material.

Moreover, the firms in this sector showed substantial movement in rankings for the social pillar. More specifically, when the S-SASB-adjusted score was used, 36\% repositioned themselves by a quartile, $9 \%$ by two quartiles, and $2 \%$ (five observations) by three quartiles. Of these last five, three belonged to SASB's Apparel Accessories and Footwear industry and the other two to Casinos and Gaming. Spearman's test established a relatively strong correlation for the social pillar rankings ( $r s=0.7160 ; p$-value $=0)$. Thus, although the change in the mean ESG score was not statistically significant for this sector, we note plenty of ranking shifts: $47 \%$ of firms moved to a different quartile according to ESG scores, $42 \%$ according to the environmental pillar score, and $47 \%$ according to the social pillar score.

In short, SASB mapping appears to have a lesser impact on social pillar than environmental pillar issues. Moreover, only one of the three sectors (Materials) showed a significant difference between the S-MSCI and S-SASB-adjusted scores. The human capital theme appeared to undergo the most changes within the social pillar, more particularly for the ESG key issues Health \& Safety, Labor Management, and Supply Chain Labor Standards.

\section{Discussion}

This study explores whether the consideration of financial materiality according to SASB's financial materiality framework has a significant impact on firms' ESG performance scores as provided by the rating agency MSCI in its MSCI ESG ratings database. The relevance of our study stems from the fact that the materiality criteria used by the main ESG rating agencies do not accurately match the financial materiality criteria that matter 
to investors, who are the main users of such ratings. We demonstrated that incorporating financial materiality into ESG performance assessment resulted in significant score differences and allowed distinguishing between firms that address substantial ESG issues and those that address mainly symbolic ESG issues that are not financially material to their business. Thus, we showed that financial materiality can improve the informative value of ESG scores and rankings, which, in turn, may result in more accurate investment analyses and better-informed investment decisions. Our findings, therefore, corroborate the view that ESG financial materiality analysis is becoming an important component of investment practices. Such integration in investment practices was demonstrated in a recent study by Consolandi, Eccles and Gabbi (2020), which showed that ESG materiality was not only a consistent effect on stock performance, but also that the financially material issues mattered more. Similarly, Kaiser [33] analyzed investment strategies and provided evidence that integrating ESG risk materiality investors increased portfolio's risk-adjusted performance.

Further, in line with the studies by Khan et al. [7] and Schiehll and Kolahgar [8], our findings support the idea that the use of SASB mapping to assess firms' ESG performance can significantly improve the informativeness of ESG scores and rankings. In fact, our results showed that for two of the three sectors studied, Materials and Consumer Staples, the SASB-adjusted score differed significantly from the original MSCI score. In addition, it is noteworthy that for all three sectors examined, the adjusted scores (SASB-adjusted scores, E-SASB-adjusted scores, and S-SASB-adjusted scores) for our sample firms were lower than the original scores (MSCI scores, E-MSCI scores, and S- MSCI scores). Our results also corroborate Boffo and Patalano's [10] findings in the sense that the ESG key issues considered in the environmental pillar were more accountable for the significant changes in ESG scores. More precisely, for all three sectors, the mean E-SASB-adjusted score was significantly different and lower than the mean E-MSCI score. Our results also indicate that the environmental theme Natural Resource Use and its ESG key issues (Water Stress, Biodiversity \& Land Use, Raw Material Sourcing) were responsible for this difference.

For the social pillar, only the Materials sector sub-sample showed a significant difference between the mean S-SASB-adjusted score and the mean S-MSCI score. Furthermore, the only social theme that showed a significant change in scores was Human Capital for the Materials and Consumer Staples sectors. This theme includes ESG key issues such as Labor Management, Health and Safety, Human Capital Development and Supply Chain Labor Standards, which are not financially material according to SASB. We also note that the firms in our sample performed relatively well on ESG key issues that SASB considers nonfinancially material. Therefore, removing them from the score calculation caused the SASB-adjusted scores to decrease.

Another notable finding in this study concerned the substantial shifts in rankings when SASB mapping was applied to assess firms' ESG performance. This movement was particularly significant for the Consumer Staples sector, which showed a very low correlation coefficient of 0.0654 between the MSCI and SASB-adjusted rankings. In addition, $74 \%$ of the observations in the Consumer Staples sector moved to a different quartile, with $27 \%$ shifting by two quartiles and $10 \%$ by three quartiles. For the Materials and Consumer Discretionary sectors, these rates were $28 \%$ and $47 \%$, respectively. The relevance of these findings is that they demonstrate that the application of ESG rankings without the financial materiality criterion may result in incomplete ESG performance assessments that lack investor informativeness.

\section{Conclusions}

This study contributes to the literature on assessment of ESG performance and its informativeness, in several ways. Firms are increasingly disclosing ESG-related information because stakeholders increasingly demand more information about ESG risks and management practices. We focus on investors' informational needs and show that ESG scores and rankings that consider financial materiality according to SASB are different from original ESG scores and therefore more likely to provide investors with relevant 
information. Regardless of the social and environmental goals, socially responsible investment is deeply rooted in the financial logic of profit maximization. Therefore, investors want to know about the financial materiality of ESG issues before they make their investment decisions. This study also has implications for governance. Although a common solution is to actively monitor firms' ESG practices and outcomes, investors may also pressure for effective internal governance, such as using financial materiality to guide ESG disclosure process.

Our results also contribute to the search for improved assessment measures for both the quality of ESG disclosure and the assessment of ESG performance. In other words, innovations in accounting standardization practices, such as the SASB standards, offer useful guides to help researchers and practitioners prepare more relevant ESG disclosures. This would be a first step toward integrating ESG information into financial reports.

As with any empirical study, ours is not without limitations. First, and related to the scope of our analysis, the focus was narrowed to firms included in the MSCI ESG Ratings database. In addition, due to the need to consider the industry specificity of ESG issues in performance assessment, we limited our comparative analysis to only three of the eleven sectors included in the MSCI database. Another potential limitation concerns the establishment of equivalent industry classifications and ESG key issues between MSCI and SASB. Although these equivalences are based on an in-depth analysis of the descriptions of each industry and key ESG issue, a certain degree of subjectivity is involved.

Despite these limitations, our findings provide useful insights into the importance of integrating financial materiality in ESG performance assessment and investment practices. Future studies could pursue this avenue by (1) reviewing the role of SASB-identified materiality in the relationship between ESG performance and financial performance; (2) applying our methodology to other sectors as well as other ESG rating systems such as the Carbon Disclosure Project (CDP) Climate, Water \& Forest Scores, and RobecoSAM's Corporate Sustainability Assessment, and (3) examining the informativeness of financially material ESG disclosures for investors. Finally, we hope that our results will warrant further research on the effects of financial materiality on ESG ratings and disclosures.

Supplementary Materials: The following are available online at https:/ / www.mdpi.com/2071-105 0/13/7/3652/s1, Table S1: Materials Sector., Table S2: Consumer Staples Sector., Table S3: Consumer Discretionary Sector, Table 4: SASB-MSCI ESG key issues correspondence map.

Author Contributions: This article is a joint work of both authors. N.M. and E.S. contributed to the development of the research idea, literature review, research methods, data collection, data analysis, and to writing the manuscript. Both authors read and approved the published version of the manuscript.

Funding: This research received financial support from Social Sciences and Humanities Research Council (SSHRC), Canada (Research Grant 435-2-18-1522), and the Autorité des marchés financiers (SC-2691).

Data Availability Statement: The data that support the findings of this study are available from MSCI ESG Ratings (https:/ /www.msci.com/our-solutions/esg-investing/esg-ratings) and Compustat (https://www.spglobal.com/marketintelligence/en/compustat-research-insight) but restrictions apply to the availability of these data, which were used under license from HEC Montréal, and so are not publicly available. Data are however available from the authors upon request.

Acknowledgments: We appreciate helpful comments from participants at the 6th ICGS Annual Conference, in November 2020, where an earlier version of this paper was presented. We are also grateful for insightful comments and suggestions provided by the Editor and two anonymous reviewers.

Conflicts of Interest: The authors declare no conflict of interest. 


\section{References}

1. Ernst \& Young. Is Your Financial Performance Revealing the True Value of Your Business to Investors? 2017. Available online: https://www.ey.com/en_gl/assurance/is-your-nonfinancial-performance-revealing-the-true-value-of-your-business (accessed on 25 January 2021).

2. Van Duuren, E.; Plantinga, A.; Scholtens, B. ESG integration and the investment management process: Fundamental investing reinvented. J. Bus. Ethics 2016, 138, 525-533. [CrossRef]

3. Friede, G.; Busch, T.; Bassen, A. ESG and financial performance. Aggregated evidence from more than 2000 empirical studies. J. Sustain. Financ. Invest. 2015, 5, 210-233. [CrossRef]

4. Orlitzky, M.; Schmidt, F.L.; Rynes, S.L. Corporate Social and Financial Performance: A Meta-Analysis. Organ. Stud. 2003, 24, 403-441. [CrossRef]

5. Amel-Zadeh, A.; Serafeim, G. Why and How Investors Use ESG Information: Evidence from a Global Survey. Financ. Anal. J. 2018, 74, 87-103. [CrossRef]

6. Steinbarth, E.; Bennett, S. Materiality Matters: Targeting the ESG Issues that Impact Performance. Harvard Law School Forum on Corporate Governance. 2018. Available online: https:/ / corpgov.law.harvard.edu/2018/05/10/materiality-matters-targeting-theesg-issues-that-impact-performance/ (accessed on 16 February 2021).

7. Khan, M.; Serafeim, G.; Yoon, A. Corporate Sustainability: First Evidence on Materiality. Account. Rev. 2016, 91, 1697-1724. [CrossRef]

8. Schiehll, E.; Kolahgar, S. Financial materiality in the informativeness of sustainability reporting. Bus. Strategy Environ. 2020. [CrossRef]

9. Chatterji, K.A.; Durand, R.; Levine, I.D.; Touboul, S. Do ratings of firms converge? Implications for managers, investors and strategy researchers. Strateg. Manag. J. 2015, 37, 1597-1614. [CrossRef]

10. Boffo, R.; Patalano, R. ESG Investing: Practices, Progress and Challenges OECD Paris. 2020. Available online: www.oecd.org/ finance/ESG-Investing-Practices-Progress-and-Challenges.pdf (accessed on 8 February 2021).

11. Truvalue Labs. ESG Data Provider Truvalue Labs ${ }^{\mathrm{TM}}$ Announces New SASB ${ }^{\mathrm{TM}}$ Edition and Significant Enhancements to its Platform. Available online: https:/ / truvaluelabs.com/news/press-release/esg-data-provider-truvalue-labs-announces-newsasb-edition-and-significant-enhancements-to-its-platform (accessed on 6 March 2021).

12. Russel Investments. Materiality Matters: Targeting the ESG Issues that Can Impact Performance. Available online: https: //russellinvestments.com/-/media/files/us/insights/institutions/governance/materiality-matters.pdf?la=en (accessed on 5 March 2021).

13. Dhaliwal, D.S.; Li, O.Z.; Tsang, A.; Yang, Y.G. Voluntary nonfinancial disclosure and the cost of equity capital: The initiation of corporate social responsibility reporting. Account. Rev. 2011, 86, 59-100. [CrossRef]

14. Plumlee, M.; Brown, D.; Hayes, R.M.; Marshall, R.S. Voluntary environmental disclosure quality and firm value: Further evidence. J. Account. Public Policy 2015, 34, 336-361. [CrossRef]

15. Clark, L.G.; Feiner, A.; Viehs, M. From the stockholder to the stakeholder. In Arabesque Partners; University of Oxford: Oxford, UK, 2015.

16. Consolandi, C.; Eccles, R.G.; Gabbi, G. How material is a material issue? Stock returns and the financial relevance and financial intensity of ESG materiality. J. Sustain. Financ. Investig. 2020. [CrossRef]

17. Diouf, D.; Boiral, O. The quality of sustainability reports and impression management: A stakeholder perspective. Account. Audit. Account. J. 2017, 30, 643-667. [CrossRef]

18. Junior, R.M.; Best, P.J.; Cotter, J. Sustainability reporting and assurance: A historical analysis on a world-wide phenomenon. J. Bus. Ethics 2014, 120, 1-11. [CrossRef]

19. KPMG International Limited. The KPMG Survey of Corporate Responsibility Reporting 2015. Available online: https://home. kpmg/xx/en/home/insights/2015/11/kpmg-international-survey-of-corporate-responsibility-reporting-2015.html (accessed on 8 March 2021).

20. Cahan, S.; De Villiers, C.; Jeter, D.; Naiker, V.; Van Staden, C. Are CSR Disclosures Value Relevant? Cross-Country Evidence. Eur. Account. Rev. 2016, 25, 579-611. [CrossRef]

21. Principles for Responsible Investment (PRI). About the PRI. Available online: https://www.unpri.org/pri/about-the-pri (accessed on 15 December 2020).

22. Grewal, J.; Hauptmann, C.; Serafeim, G. Material Sustainability Information and Stock Price Informativeness. J. Bus. Ethics 2020. [CrossRef]

23. Brulhart, F.; Gherra, S. Management des parties prenantes, pro-activité environnementale et rentabilité: Le cas du secteur des produits de grande consommation en France. Financ. Contrôle Strat. 2013, 16, 1-36. [CrossRef]

24. United States Supreme Court. TSC Industries, Inc. v. Northway, Inc., 426 U.S. 438 (1976). Available online: https:/ / supreme. justia.com/cases/federal/us/426/438/ (accessed on 6 March 2021).

25. Sustainability Accounting Standard Board (SASB). Standards Overview. Available online: https://www.sasb.org/standardsoverview / (accessed on 12 November 2020).

26. Kumar, R.; Weiner, A. The ESG Data Challenge. State Street Global Advisors. 2019. Available online: https://www.ssga.com/ investment-topics/environmental-social-governance/2019/03/esg-data-challenge.pdf (accessed on 5 March 2021). 
27. Declan Harty. Index Providers Race to Meet Booming Demand for ESG Data. Available online: https:/ /www.spglobal.com/ marketintelligence/en/news-insights/trending/di5a_NO_q6j8iPKWBEEyqw2 (accessed on 8 January 2020).

28. Morgan Stanley Capital International (MSCI). MSCI ESG Ratings Methodology. Available online: https://www.msci.com/ documents/1296102/21901542/MSCI+ESG+Ratings+Methodology+-+Exec+Summary+Nov+2020.pdf (accessed on 4 February 2021).

29. Morgan Stanley Capital International (MSCI). The Global Industry Classification Standard (GICS). Available online: https: / / www.msci.com/gics (accessed on 6 March 2021).

30. Sustainability Accounting Standard Board (SASB). SASB Materiality Map. Available online: https://materiality.sasb.org/ (accessed on 4 March 2021).

31. Sustainability Accounting Standard Board (SASB). Find Your Industry. Available online: https://www.sasb.org/find-yourindustry/ (accessed on 4 March 2021).

32. Abramo, G.; D'Angelo, C.A.; Felici, G. Informed peer review for publication assessments: Are improved impact measures worth the hassle? Quant. Sci. Stud. 2020, 1, 1321-1333. [CrossRef]

33. Kaiser, L. ESG integration: Value, growth and momentum. J. Asset Manag. 2020, 21, 32-51. [CrossRef] 